\title{
The Fate of Activated Group 2 Innate Lymphoid Cells
}

\author{
Laura Mathä ${ }^{1}$, Itziar Martinez-Gonzalez ${ }^{2 \dagger}$, Catherine A. Steer ${ }^{1 \dagger}$ and Fumio Takei ${ }^{1,3^{*}}$ \\ 1 Terry Fox Laboratory, British Columbia Cancer, Vancouver, BC, Canada, ${ }^{2}$ Department of Microbiology, Tumor and Cell \\ Biology, Karolinska Institutet, Solna, Sweden, ${ }^{3}$ Department of Pathology and Laboratory Medicine, University of British \\ Columbia, Vancouver, BC, Canada
}

Group 2 innate lymphoid cells (ILC2s) reside in both mucosal and non-mucosal tissues and play critical roles in the first line of defense against parasites and irritants such as allergens. Upon activation by cytokines released from epithelial and stromal cells during tissue damage or stimulation, ILC2s produce copious amounts of IL-5 and IL-13, leading to type 2 inflammation. Over the past 10 years, ILC2 involvement in a variety of human diseases has been unveiled. However, questions remain as to the fate of ILC2s after activation and how that might impact their role in chronic inflammatory diseases such as asthma and fibrosis. Here, we review studies that have revealed novel properties of postactivation ILC2s including the generation of immunological memory, exhausted-like phenotype, transdifferentiation and activation-induced migration.

Reviewed by:

Padraic Fallon,

Trinity College Dublin,

Ireland

Timotheus You Fu Halim, University of Cambridge, United Kingdom

*Correspondence: Fumio Takei ftakei@bccrc.ca

${ }^{+}$These authors have contributed equally to this work

Keywords: innate lymphoid cells, type 2 inflammation, mucosal immunity, immunological memory, neonatal immunity, exhaustion, transdifferentiation, migration

\section{INTRODUCTION}

Group 2 innate lymphoid cells (ILC2s) belong to the family of innate lymphoid cells that include natural killer (NK) cells, helper innate lymphoid cells (ILCs) and lymphoid tissue inducer (LTi) cells, which all share a common lineage. Helper ILCs are classified into three groups, based on their similarities to helper $\mathrm{T}$ cell subtypes with respect to the expression of transcription factors and effector cytokines: ILC1s are T-bet ${ }^{+}$and produce interferon (IFN) $\gamma$, ILC2s highly express GATA3 and release IL-5 and IL-13, while ILC3s are dependent on RAR-related orphan receptor (ROR) $\gamma t$ and secrete IL-22 and IL-17 (1). ILC2s were first identified in 2010 as a population of innate immune cells with a lymphoid morphology which lacks the expression of lineage markers commonly expressed by T, B and myeloid cells (2-4). They were initially termed natural helper cells (2), nuocytes (3) or innate helper type 2 (Ih2) cells (4), but unification of their nomenclature was proposed in 2013, and are now called ILC2s (5). Since their initial discovery in the gut, they have been identified in various other organs in mice, including the lung (6-8), skin (9-11), adipose tissues (12-14), liver (15), pancreas (16) and heart $(17,18)$, as well as in humans $(6,9,10,13,19)$ and their pathologic and protective roles in multiple human diseases such as asthma, atopic dermatitis and fibrosis, and infections have been described. ILC2s also play a critical role in adipose tissue homeostasis by sustaining type 2 immunity and promoting beiging of white adipose tissue (12-14), while an ILC2-tuft cell circuit orchestrates intestinal homeostasis and remodeling $(20,21)$.

ILC2s are known to seed tissues early during development and adapt to environmental cues (22-27); consequently, their phenotype slightly differs depending on their residing organs (Table 1). 
MouseILC2s express CD45, IL-7R $\alpha$ (CD127), CD90 (Thy1) and IL-2R $\alpha$ (CD25) (2-4), while CD103 (11) and IL-18R $\alpha$ (22) are uniquely expressed by skin ILC2s. In contrast, the expression of IL-33 receptor (ST2) and IL-25 receptor varies depending on the organ. ST2 is expressed by the lung $(6,8)$, liver (15) and adipose tissue ILC2s (12-14), while ILC2s in the small intestine (SI) express low levels of this receptor (28) and the expression levels vary in the skin $(9,22,28)$. In contrast, IL-25R is highly expressed by SI ILC2s (20), while adipose tissue ILC2s do not express IL25R (22) and both IL-25R positive and low/negative ILC2s have been reported in the skin $(11,20,22)$. Interestingly, we have previously shown that the majority of naïve lung ILC2s are negative for this marker, whereas its expression is induced by activation (29).

ILC2s in human peripheral blood (PB) are similar to mouse tissue ILC2s in that they express CD127 and CD25, but are uniquely identified by the expression of chemoattractant receptor-homologous molecule expressed on Th2 cells (CRTH2) and CD161 (19). Unlike mouse ILC2s, human PB ILC2s lack the expression of CD90, ST2, IL-25R and CD103 (19, 30,31 ), whereas they are positive for IL-18R $\alpha$ expression (31).

Due to the species and tissue differences in surface molecule expression and the lack of universal markers for ILC2s, identification of ILC2s can be challenging. Additionally, some surface molecules are downregulated or upregulated upon ILC2 activation or in disease conditions, making it more difficult to definitively identify them. However, the transcription factor GATA3 is highly expressed by mouse and human ILC2s, and therefore, it is a useful marker for ILC2 identification $(32,33)$.

\section{ACTIVATION OF ILC2s}

ILC2s lack antigen specific receptors and hence, their activation is finely regulated by a repertoire of molecules including cytokines, neurotransmitters and lipid mediators. Here, we review the activation of ILC2s by cytokines (direct) and allergens (indirect). The regulation of ILC2 activation and inhibition by other molecules is reviewed in great detail elsewhere $(34,35)$. Upon activation, ILC2s produce IL-5 and IL-13 among others, resulting in type 2 inflammation characterized by eosinophilia, alternative activation of macrophages, type 2 helper T (Th2) cell differentiation and IgE class switching.

\section{Direct Activation by Cytokines}

Alarmins are molecules that are normally present within cells and released upon tissue injury, environmental insults, physiological stress or necrosis (36). They induce activation of various immune cells, resulting in sterile inflammation. ILC2s express receptors for an alarmin cytokine, IL-33, and other secreted cytokines such as IL25 , thymic stromal lymphopoietin (TSLP) and IL-18, and are potently activated by these cytokines.

IL-33 is constitutively expressed in the nuclei of endothelial cells, epithelial cells, fibroblastic reticular cells and adventitial stromal cells (37-42), while IL-25 can be either constitutively expressed as seen in tuft cells (21), or its expression can be induced in immune cells, such as alveolar macrophages (43), mast cells (44), basophils, eosinophils (45) and Th2 cells (46). TSLP expression is induced in epithelial cells in the lung, such as alveolar type II cells (42), whereas it is constitutively expressed in the large intestine $(47,48)$. Stimulation of IL-33 and IL-25 signaling pathways through their cognate receptors consisting of ST2 and IL-1 receptor accessory protein (IL-1RAcP) (49), and IL-17RA and IL-17RB (50), respectively, induces activation of nuclear factor $(\mathrm{NF}) \kappa B$ and mitogen-activated protein kinase (MAPK) $(50,51)$. This leads to phosphorylation of GATA3, promoting its binding to Il5 and Ill3 promoters and ILC2 proliferation (52). TSLP binds to the receptor comprised of IL7R $\alpha$ and TSLPR (53) and activates a separate downstream signaling pathway involving Janus kinase (JAK) $1 / 2$ and STAT5 (54). STAT5 binds to the Gata3 gene and together, they regulate ST2 expression, enhancing IL-33 induced activation (55).

In vivo responsiveness of ILC2s towards cytokine stimulation varies depending on their residing tissues. Intranasal (i.n.) administration of recombinant IL-33 potently activates lung ILC2s $(29,56,57)$. In contrast, naïve adult lung ILC2s do not respond to i.n. IL-25 or TSLP administration (29, 42, 56, 58, 59). Interestingly, lung ILC2s upregulate IL-25R as they acquire memory-like properties after allergen or IL-33 treatment and become responsive to IL-25 stimulation (29). We have also shown that naïve neonatal lung ILC2s are potently stimulated by IL-25 (27). Unlike lung ILC2s, ILC2s in mesenteric lymph nodes $(\mathrm{mLN})$, spleen and liver expands upon intraperitoneal (i.p.) administration of IL-25 $(3,4)$. Moreover, IL-25 deficient mice have significantly reduced ILC2s in the SI at steady state and after worm infection, suggesting a critical role of IL-25 in maintenance and activation of intestinal ILC2s (21). IL-25 also serves as the predominant cytokine for skin ILC2 activation in $\mathrm{BALB} / \mathrm{c}$ mice (10).

Despite their potency in activating ILC2s in vivo, IL-33 or IL-25 alone is not sufficient to induce ILC2 activation in vitro, suggesting that activation of ILC2s requires a secondary signal provided by co-stimulatory cytokines such as IL-2 and IL-7 $(2,7,10)$.

It was recently shown that the majority of mouse skin ILC2s express IL-18R $\alpha$ (22). Consequently, ILC2s isolated from skin are weakly activated upon in vitro stimulation by IL-18 + TSLP compared to TSLP only, which does not activate them (22). ILC2 stimulation through this pathway is physiologically significant, as IL-18 deficient mice have impaired skin ILC2 activation and type 2 inflammation in a mouse model of atopic dermatitis-like disease (22). Of note, IL-18 mediated activation of ILC2 is independent of IL-33, IL-25 and TSLP (22). Human PB ILC2s, unlike mouse ILC2s, respond very potently to in vitro IL-18 + IL-7 stimulation by producing type 2 cytokines (31), suggesting that IL-18 may play a more essential role in human ILC2 biology.

\section{Indirect Activation by Allergens}

ILC2s play a crucial role in airway allergic diseases induced by various allergens in experimental mouse models. Due to the lack of antigen specific receptors, ILC2s do not directly recognize and respond to allergens. Instead, they are stimulated by various 
cytokines released upon irritation or tissue injury caused by allergen inhalation.

In murine models, various allergens including house dust mite $(\operatorname{HDM})(56,57,60,61)$, chitin $(62)$, papain $(29,63)$, fungal allergens from Alternaria (64-66) and Aspergillus (29) species and ovalbumin (OVA) $(56,58)$ have been shown to activate lung ILC2s. Treatment with these allergens causes disruption of the barrier integrity and induces the release of ILC2-activating cytokines from the airway epithelial cells (7, 42, 59, 64, 66-69). As Crlf2 (TSLPR), Il25 and Il1rl1 (ST2) triple-deficient mice have similar numbers of ILC2s as wild-type mice upon chitin treatment (62), and $I l 33^{-/-}$mice have normal ILC2 accumulation in bronchoalveolar lavage fluid (BALF) after HDM administration (70), these cytokines may not be necessary for ILC2 proliferation upon allergen stimulation. However, they appear to play a critical role in ILC2 activation as $I l 33^{-/-}$or $I l 1 r l 1^{-/-}$mice have reduced ILC2 cytokine production compared to wild-type mice in papain, Alternaria and HDM models $(63,64,70)$, and mice deficient in one or more ILC2activating cytokine signaling pathways show significantly reduced expansion of eosinophils and alternatively activated macrophages (AAM) after chitin treatment (62).

Interestingly, HDM driven ILC2 expansion requires $\mathrm{T}$ cell activation, as mice with impaired $\mathrm{T}$ cell activation do not mount ILC2-mediated type 2 inflammation upon HDM challenge (70), while adaptive lymphocytes are not necessary in the papain model, as i.n. papain treatment into $\operatorname{Rag}^{-/-}$mice leads to normal ILC2 activation and eosinophilia (7). In contrast, ILC2s are not required for allergic inflammation in an OVA model, in which Th2 cells are stimulated by OVA plus adjuvant alum, as ILC2 deficient mice show no impairment of type 2 immune responses (61). These data suggest that immunological environment induced by these allergens seems to vary and the role of ILC2s in type 2 inflammation may be slightly different in each model.

\section{FUNCTION OF ILC2s}

Upon activation, lung ILC2s secrete copious amounts of type 2 cytokines, IL-5 and IL-13 but also IL-9 and amphiregulin $(6,7$,
42, 71, 72). IL-5 induces eosinophil development and recruitment, resulting in eosinophilia in the lung (73). IL-13 causes goblet cell hyperplasia, followed by mucus hyperproduction, smooth muscle contraction and subepithelial fibrosis, resulting in tissue remodeling and airway hyperresponsiveness (74). Moreover, together with IL-4, IL-13 provides cues for macrophage differentiation into AAM (74). ILC2-derived IL-13 has been shown to disrupt tight junctions in the epithelial lining of the lung causing leakiness of the airways (75). It also facilitates differentiation of helper $\mathrm{T}$ cells into Th2 type by inducing migration of activated dendritic cells to the draining LN (63), further enhancing type 2 inflammation. In addition to type 2 cytokines, ILC2s transiently produce IL- 9 early during inflammation $(42,71,72)$, which provides signals for mast cell accumulation and airway remodeling by inducing goblet cell hyperplasia $(76,77)$. IL-9 also promotes survival (72) and/or activation (42) of ILC2s in an autocrine/paracrine manner $(42,71)$, resulting in amplification of IL-5 and IL13 production.

More recent studies have shown that IL-10 producing ILC2s, termed "ILC2 $2_{10}$ " and "exhausted ILC2s" (discussed in more detail later) are generated in the mouse lung during chronic inflammation or in response to IL-2 $(78,79)$. The release of IL-10 can also be induced by mouse lung and SI ILC2s in vitro by various stimulants, including IL-2, IL-10, IL-27, IL-4, retinoic acid (RA) or neuromedin $U(78,80)$. Interestingly, blocking IL10 results in a reduction in IL-10 production from ILC2s, suggesting an autocrine/paracrine regulation by IL-10 (80). In humans, a $\mathrm{KLRG}^{+}$subset of ILC2s secrete IL-10 when stimulated in the presence of RA $(81,82)$. While GATA3 expression confirms their ILC2 lineage identity, IL- $10^{+}$ILC2s express CTLA4 and CD25, resembling regulatory T cells $(81,82)$. Consequently, they inhibit various $\mathrm{CD} 4^{+}$helper $\mathrm{T}$ cell subsets and ILC2s in an IL-10 dependent manner (81, 82), suggesting previously unappreciated immune regulatory role of ILC2s.

In addition to soluble mediators like cytokines, ILC2s directly interact with other ILC2s and lymphocytes through a repertoire of surface molecules. ILC2s have been shown to directly facilitate Th2 polarization through $\mathrm{PD}-1 / \mathrm{PD}-\mathrm{L} 1$ interaction during Nippostrongylus brasiliensis infection (83), while IL-33

TABLE 1 | Summary of ILC2 phenotypes.

\begin{tabular}{|c|c|c|c|c|c|c|}
\hline & \multicolumn{5}{|c|}{ Mouse } & $\frac{\text { Human }}{\text { Blood }}$ \\
\hline CD90 & + & + & + & + & + & - \\
\hline CD25 & + & + & + & + & + & + \\
\hline CD103 & ND & ND & + & ND & ND & - \\
\hline IL-18R $\alpha$ & - & - & + & - & - & + \\
\hline \multicolumn{6}{|l|}{ CRTH2* } & + \\
\hline \multicolumn{6}{|l|}{ CD161* } & + \\
\hline GATA3 & + & + & + & + & + & + \\
\hline
\end{tabular}

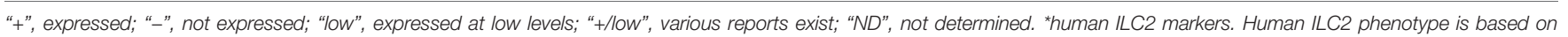
peripheral blood ILC2s. 
activated ILC2s stimulate Th2 and regulatory T cells via OX40/ OX40L interaction (84). Activated ILC2s, expressing ICOS ligand (ICOSL), also promote accumulation of ICOS ${ }^{\text {high }}$ regulatory $\mathrm{T}$ cells through ICOS/ICOSL interactions (85). Interestingly, ILC2s express both ICOS and ICOSL and provide survival signals to each other (86).

Due to ILC2's potent capacity to produce cytokines, they initiate robust type 2 immune responses upon epithelial injury or environmental insults, and consequently, they are implicated in pathogenesis of various airway diseases, including asthma (87, 88), chronic rhinosinusitis with nasal polyps (CRSwNP) (19, 89-93), allergic rhinitis (94) and pulmonary fibrosis (95-97), and respiratory infections caused by influenza (8) and respiratory syncytial $(98,99)$ viruses. In contrast, ILC2s play a crucial protective role during influenza virus infections by producing amphiregulin, which facilitates the repair of damaged airway epithelium and restores the impaired lung function caused by influenza (6). Moreover, human IL- $10^{+}$ ILC2s prevent the loss of epithelial barrier integrity upon allergen exposure (81), suggesting a protective role in airway allergic diseases. Overall, the role of ILC2s in type 2 inflammation seem to vary in different models and diseases.

\section{THE FATE OF ACTIVATED ILC2s}

Once activated and having proliferated, lung ILC2s propagate a series of inflammatory events by production of type 2 cytokines as described above. The majority of activated lung ILC2s remain in the lung $(23,100,101)$ and presumably die once their task is completed, although activation-induced death of ILC2s has not yet been studied. A small proportion of activated lung ILC2s persists in the lung as memory-like ILC2s (29), or becomes exhausted (79). Some ILC2s may transdifferentiate into other types of ILCs under specific conditions (102-106), whereas it was recently found that a subset of ILC2s leaves the residing organs and circulates (101, 107) (Figure 1, Table 2).

\section{ILC2 Memory}

Immunological memory is the ability of immune cells to recall a previous encounter with a specific antigen and mount robust responses upon subsequent exposures to the same antigen. The acquisition of immunological memory is a hallmark of adaptive immunity and innate leukocytes have long been thought to not possess the ability to remember previous activation. However, with the discovery of memory NK cells (110-113), the potential

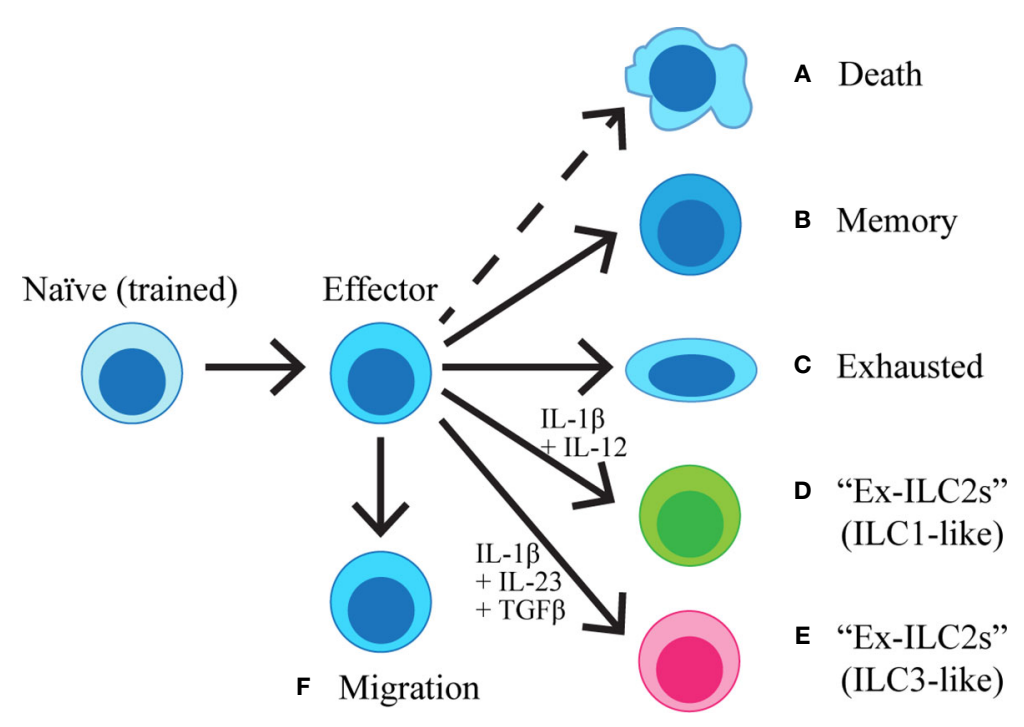

FIGURE 1 | Naiive ILC2s are exposed to IL-33 during the neonatal period and become "trained". Once activated, ILC2s become effector cells, producing cytokines and initiating the inflammatory cascade. The majority of the effector cells are predicted to die (A), while a proportion of ILC2s acquires immunological memory (B). Some ILC2s may become exhausted (C), whereas others can also transdifferentiate into IFN $\gamma$-producing ILC1-like cells (D) or IL-17-producing ILC3-like cells (E) upon stimulation with IL-1 $\beta+$ IL-12 or IL-1 $\beta+$ IL-23 + TGF $\beta$, respectively. A subset of ILC2s migrates out of the lung and enter circulation (F).

TABLE 2 | The fate of activated ILC2S.

\begin{tabular}{|c|c|c|}
\hline & Models (mouse/human) & References \\
\hline Immunological memory/trained immunity & Mouse & $(27,29,108)$ \\
\hline Exhaustion & Mouse & (79) \\
\hline \multirow[t]{2}{*}{ Transdifferentiation to ILC1s } & Human & $(102-104)$ \\
\hline & Mouse & $(103)$ \\
\hline Transdifferentiation to ILC3s & Human & $(105,106)$ \\
\hline Activation-induced migration & Mouse & $(101,107,109)$ \\
\hline
\end{tabular}


of innate lymphocytes to acquire memory-like properties have been unraveled. Detailed reviews of immunological memory of ILC2s and innate leukocytes can be found elsewhere $(114,115)$.

\section{Memory ILC2s in Mouse}

We have recently shown that lung ILC2s can acquire immunological memory (29). Upon allergen inhalation, mouse lung epithelium releases alarmins such as IL-33, which activates lung resident ILC2s. This results in a vigorous expansion of ILC2s, followed by a contraction phase and resolution of lung inflammation as indicated by the decrease in lung eosinophils and BALF type 2 cytokines. While the number of ILC2s continues to decrease after the peak of inflammation, some of the activated ILC2s survive for a long time as shown by persistence of ILC2s labelled with bromodeoxyuridine (BrdU), which was administered at the time of initial activation (29). These ILC2s are more responsive to a secondary stimulus compared to naïve ILC2s, which is a feature of immunological memory, and hence, were termed "memory-like ILC2s" (29). However, unlike antigen specific T and B cells, ILC2s do not recognize specific antigens and consequently, memory-like ILC2s are able to mount robust immune responses to subsequent stimulation by unrelated allergens or cytokines. Memory-like ILC2s are defined by changes in the expression of a small subset of genes compared to naïve or effector ILC2s (29). These changes include the upregulation of $I l 17 r b$, a subunit of the IL-25 receptor complex, which enables them to uniquely react to in vivo IL-25 stimulation, unlike naïve lung ILC2s. Although adoptive transfer of memory-like ILC2s and gene expression data indicate that the acquisition of immunological memory is cellintrinsic (29), we cannot rule out the possibility that environmental components may be required to mount an efficient recall response.

A similar memory-like ILC2 population has been demonstrated in mouse models of nematode infections. Yasuda et al. found that ILC2s persist in BALF for at least 1 month after infection of mice with the migratory helminth Strongyloides venezuelensis, while other immune cell numbers go back to similar levels as in naïve mice (108). Upon challenge with the unrelated nematode $N$. brasiliensis a month later, mice preinfected with $S$. venezuelensis demonstrate protective effects against $N$. brasiliensis infection, accompanied by increased number of ILC2s and cytokines in the BALF of pre-infected mice compared to those without primary infection. The protective effect is not specific to $S$. venezuelensis, as similar results are obtained when the order of infection is switched (108). In contrast, IL-33 pre-treatment fails to induce a similar protection (108). The resistance against $N$. brasiliensis infection is independent of $\mathrm{CD} 4^{+} \mathrm{T}$ cells, suggesting a primary role of ILC2s, whereas IL-33 and eosinophils are critical. Unlike the memory-like ILC2s we have previously described (29), the enhanced responsiveness of ILC2s upon challenge infection by nematodes is not mediated by IL-25R upregulation and hence, the authors named these cells "trained ILC2s (108)."

Seehus and colleagues have defined a new subset of IL-10 producing ILC2s in mouse lungs, termed "ILC2 10 " (78). These cells are generated upon i.p. administration of high dose IL-33 or chronic stimulation with i.n. papain treatment and act as regulatory cells with an immunosuppressive function. Interestingly, although ILC2 10 contracts quickly upon withdrawal of stimulation, administration of a single dose of IL-33 a month after the initial stimulation induces an increased number of ILC2 $2_{10}$ in pre-treated mice compared to untreated mice (78). Therefore, it is likely that immunological memory can be acquired by different subsets of ILC2s and this may have implications not only in the exacerbation but also in regulation of lung inflammation.

It is important to note that in vitro or in vivo primed Th2 cells can also demonstrate innate-like properties by responding to cytokines or unrelated antigens (116). Such innate-like behavior of Th2 cells is TCR independent and requires IL-33, suggesting that it is an antigen non-specific response (116). Th2 cells in mice inoculated with $N$. brasiliensis can mount an efficient airway eosinophilic inflammation upon HDM challenge 3-4 weeks later, suggesting their resemblance to the innate immunological memory of ILC2s (116). Therefore, immunological memory should be defined as the capacity of immune cells to remember previous activation and respond more efficiently upon reactivation despite antigen specificity (114).

\section{Memory ILC2s in Human}

Although immunological memory-like properties have been described in human NK cells $(117,118)$, there is little evidence of memory ILC2s in human. A recent paper by van der Ploeg identified the human counterpart of the inflammatory ILC2s (ilLC2s) (119), which is a subtype of ILC2s induced during inflammation (discussed in more detail later) (109). These human iILC2s, characterised by the expression of CD45R isoform CD45RO, are enriched in the blood and nasal polyps of patients with CRSwNP and in the blood of asthma patients, and are highly activated. CD45RO ${ }^{+}$ILC2s differentiate from resting $\mathrm{CD}_{45 \mathrm{RA}}^{+}$ILC2s isolated from $\mathrm{PB}$ upon in vitro cytokine stimulation. While CD45RO is a marker for human memory $\mathrm{T}$ cells (120), whether or not some of these highly activated ilLC2s are able to retain the expression of CD45RO and become memory ILC2s remains to be explored.

\section{Trained ILC2s (Neonatal ILC2s)}

In vivo lineage-tracing experiments have revealed that a portion of steady-state ILC2s in various mouse tissues originates in the neonatal period and persists into adulthood $(23,27)$. ILC2s are undetectable in the lung of newborn mice, but ILC2 numbers rapidly increase in the following 10 days and peak on postnatal days 10-14 when the numbers reach to $\sim 2-3$ times of those in adult mouse lungs (24-26). In parallel to the ILC2 expansion, the level of IL-33 expression is significantly higher in neonatal lungs than adult lungs $(24,26,27)$. It is thought that endogenous IL-33 is released from stromal cells in the neonatal period (41) due to postnatal mechanical stress from the first newborn breaths (26), development $(25)$, or hyperoxia $(24,121)$. At the peak of their expansion, neonatal ILC2s upregulate activation-related genes such as Mki67, Il13, Il5, and Il1r2, increase intracellular expression of IL-13 and IL-5, and expression of Ki67 and IL25R (24, 27). Neonatal lungs also have ILC2-dependent 
eosinophilia $(24,26,27)$. In IL-33 deficient pups, ILC2s develop normally but they do not expand as in wild-type pups and their activation is not observed $(24,26)$. Administration of recombinant sST2, a decoy receptor that blocks IL-33 signaling, also inhibits the activation of neonatal lung ILC2s (25). These studies together showed that neonatal lung ILC2s are activated by endogenous IL-33.

While the neonatal lung ILC2s contract to adult levels around 3 weeks of age, ILC2s labeled by i.n. BrdU administration during the expansion phase persist into adulthood (27). Schneider et al. also irreversibly marked neonatal ILC2s by tamoxifen-induced Cre expression and red fluorescent protein (RFP) and showed that RFP-marked neonatal ILC2s persist for many months and are only very slowly replaced by RFP-negative ILC2s in adulthood (23). Therefore, ILC2s that develop in the neonatal period become tissue resident cells in adulthood. Interestingly, i.n. injections of IL-33 into adult mice previously given BrdU in the neonatal period more intensely activate BrdU-positive than negative lung ILC2s (27). Lung ILC2s in adult IL-33 knock out (KO) mice do not respond as intensely to i.n. IL-33 stimulation as wild-type ILC2s, and i.n. administration of IL-33 in the neonatal period reverses the impaired response of ILC2s in IL$33 \mathrm{KO}$ mice in adulthood (27). Ricardo-Gonzalez et al. also showed that absence of IL-33 signaling leads to downregulation of adult ILC2 type 2 signatures (22). These studies suggested that activation of lung ILC2s by endogenous IL-33 in the neonatal period has long lasting effects on ILC2 functions in adulthood and the effect was termed "ILC2 training (27)." The idea of trained ILC2s implies that lung resident ILC2s in adult mice are more responsive to stimuli than ILC2s that develop in adulthood as the former are trained in the neonatal period whereas the latter are untrained, similar to ILC2s in IL$33 \mathrm{KO}$ mice.

It should be noted that there are significant differences between memory-like ILC2s and neonatally trained ILC2s. Neonatal ILC2s transiently upregulate IL-25R but the levels diminish into adulthood and adult lung ILC2s do not respond to i.n. IL-25 stimulation (27). In contrast, memory-like ILC2s maintain IL-25R expression and are activated by i.n. IL-25 treatment (29).

\section{Exhausted ILC2s}

Exhaustion of lymphocytes occurs upon persistent antigen stimulation, where immunological memory generation fails and cells are also unable to execute effector functions (122). Miyamoto et al. reported that ILC2s lacking core binding factor (Cbf) $\beta$ showed an activated phenotype at steady state but a hyporesponsive phenotype upon in vitro stimulation (79). The gene expression profiles of Cbf $\beta$ deficient ILC2s stimulated by IL-33 in vitro resemble those of exhausted $\mathrm{CD}^{+} \mathrm{T}$ cells, and hence, these cells were termed "exhausted-like ILC2s". A similar population of exhausted-like ILC2s, defined by their expression of IL-10 and TIGIT, are generated in a severe subacute asthma model, where wild-type mice are treated with high doses of papain short-term (79). These ILC2s, which express killer cell lectin-like receptor G1 (KLRG1), programmed cell death protein 1 (PD-1) and glucocorticoid-induced TNFR-related (GITR), appear in the BALF, where the inflammation is the most severe, but not in the lung. They do not proliferate well nor do they produce much type 2 cytokines. The exhausted-like ILC2s are also generated in the lung as well as in the BALF when wildtype mice receive a high-dose papain treatment every 3 days over a month period (79). The exhausted phenotype of ILC2s is further enhanced by Cbf $\beta$ deficiency, suggesting that the ILC2 exhaustion process is inhibited by Runx/Cbf $\beta$ complex. It is important to note that exhausted-like ILC2s are different from previously-described ILC2 10 (78), as the former lacks the ability to efficiently produce type 2 cytokines, whereas the latter is a great producer of type 2 cytokines.

\section{Ex-ILC2s}

Plasticity of ILC2s towards IFN $\gamma$ producing ILC1s (102-104) and IL-17 producing ILC3s $(105,106)$ have been documented. An indication of ILC2's capacity to transdifferentiate into ILC1s came from the observation that PB and lung samples collected from chronic obstructive pulmonary disease (COPD) patients are enriched in ILC1s whereas the frequency of ILC2s is reduced compared to healthy subjects or less severe COPD patients (102, 103). In vitro stimulation of ILC2s isolated from $P B$ of healthy donors in the presence of IL-2, IL-1 $\beta$ (or IL-33 + TSLP) and IL12 causes the loss of ILC2 signatures, such as GATA3, IL- 5 and IL-13, and upregulation of ILC1 features, T-bet and IFN $\gamma$ expression $(102,104)$. Priming of ILC 2 s with IL-1 $\beta$ is necessary, during which IL- $1 \beta$ epigenetically modifies the transcriptome of ILC2s, shifting it to a more ILC1-like profile (104). Interestingly, the ILC2 phenotype is restored when exILC2s are stimulated with IL-4, whereas true ILC1s do not covert to ILC2s upon IL-4 stimulation (102). A similar transdifferentiation of ILC2s to ILC1s have been shown in mice using a model of influenza infection, where immunodeficient mice adoptively transferred with $\mathrm{GFP}^{+}$ILC2s were infected with influenza virus (103). $\mathrm{GFP}^{+}$ILC2s underwent downregulation of GATA3 and upregulation of IL-18R $\alpha$ and IL$12 \mathrm{R} \beta 2$, and produced IFN $\gamma$ upon ex vivo stimulation with IL-12 and IL-18 (103).

Human ILC2s have also been shown to have the capacity to convert into IL-17 producing Ckit ${ }^{+} \mathrm{NKp} 44^{-}$ILC3-like cells when cultured in the presence of IL- 2 + IL-1 $\beta$ + IL-23 + TGF $\beta$ (105, 106). This transdifferentiation is associated with downregulation of GATA3, followed by upregulation of ROR $\gamma t$ expression and IL-17 production (105). IL-1 $\beta$ is required for IL-17 production, while TGF $\beta$ further promotes transdifferentiation by enhancing IL-17 production and ROR $\gamma$ t expression, and inhibiting IL-5 production $(105,106)$. ILC2 phenotype and function are partially restored in IL-17 ${ }^{+}$ILC2s upon IL-4 stimulation. A marked increase in NKp44- ILC3s is observed in psoriatic lesions and nasal polyps collected from cystic fibrosis patients $(105,106)$, suggesting that ILC2 transdifferentiation into ILC3s is physiologically relevant in the presence of the appropriate cytokine milieu.

Notably, the majority of studies demonstrating ILC2 plasticity have been performed using human samples. It is most likely due to the fact that human ILCs are constantly exposed to various stimuli and hence, their identities as different subsets of ILCs are 
more ambiguous than in mice, which are maintained relatively sterile in animal facilities. Therefore, it is more feasible to induce transdifferentiation of human ILC2s into ILC1s or ILC3s upon stimulation with type 1 or type 3 skewing cytokines, respectively, compared to mouse ILC2s.

\section{Migration of ILC2s}

The majority of mouse lung ILC2s are generated during the neonatal period and there is a limited amount of de novo generation of ILC2s during adulthood (23). The idea of ILC tissue residency was first proposed by Gasteiger and colleagues, where they examined the composition of ILC pools at homeostasis and during inflammation using a parabiosis model (100). At steady state, more than 95\% of ILCs are host-derived in all tissues analyzed, including the SI, salivary gland, lung and the liver (100). Upon infection with the migratory helminth, $N$. brasiliensis, the composition of donor and host-derived ILC2s in the lung, SI and mLN remains unchanged during the early stage of helminth infection, indicating that ILC2s are tissue resident lymphocytes unlike circulatory $\mathrm{T}$ and $\mathrm{B}$ cells.

While tissue residency of ILC2s is a well-established concept in the mouse system, in humans we can extrapolate from the presence of elevated ILC2s in asthmatic patients' PB (88) that ILC2s may have the capacity to circulate or migrate. In mice, despite limited influx of hematogenous sources of ILC2s at homeostasis or during inflammation, i.p. IL-25 treatment or $N$. brasiliensis infection causes circulation of ilLC2s, an inflammation-induced population of ILC2s identified as $\mathrm{Lin}^{-}$ $\mathrm{KLRG}^{+}{ }^{+} \mathrm{ST} 2^{\text {lo }}$ cells $(107,109)$. ilLC2s originate in the SI, from which they enter the lymphatic and blood circulation before reaching the peripheral organs. We have also previously shown that activation of ILC2s in the lung by i.n. IL-33 or papain treatment causes accumulation of ILC2s in the draining mediastinal LN (29). Although we did not specifically investigate their migration from the lung to the $\mathrm{LN}$, these data together with iILC2 migration indicate that migratory behavior of ILC2s may be induced upon activation (Figure 2).

A recent report by Ricardo-Gonzalez et al. examined the source of circulating ILC2s upon $N$. brasiliensis infection using fate-mapping models (101). Upon subcutaneous administration, $N$. brasiliensis first migrates to the lung, where it is coughed up and swallowed, entering the digestive tract, reaching the intestine (123). Early during the parasite infection (day 5), the majority of circulating ILC2s are dependent on IL-25 signaling and are of intestinal origin. In contrast, lung ILC2s, dependent on IL-33 signaling appear in circulation later during infection (day 12). These results demonstrate that in spite of their tissue residency at homeostasis and during inflammation, local activation of ILC2s can cause systemic dissemination of type 2 inflammation by inducing migratory behavior of ILC2s. It remains to be determined whether the circulating ILC2s return to their residing organs or migrate to other tissues.

\section{CONCLUDING REMARKS}

The past few years of research on ILC2s at mucosal and nonmucosal sites has provided a wealth of knowledge regarding the

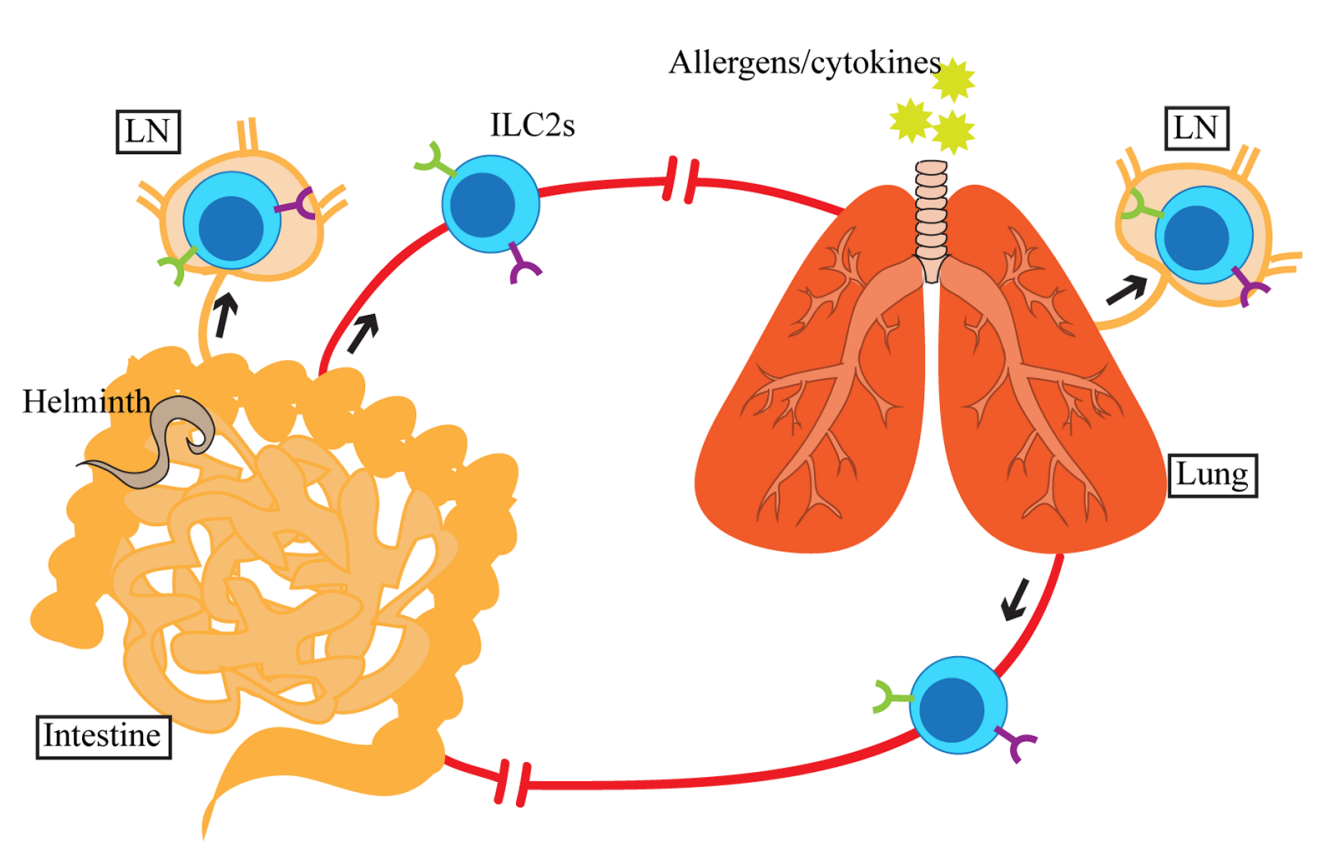

FIGURE 2 | Upon activation by allergens, cytokines or helminths in the lung or small intestine (SI), ILC2s and inflammatory ILC2s (ilLC2s) appear in circulation as well as in the tissue-draining lymph nodes (LN). SI-derived ilLC2s migrate to the lung, whereas the destination of activated SI and lung ILC2s is currently unclear. Although ILC2s and ilLC2s are detected in blood and LN, which suggests that their migration involves lymphatics and blood, the exact route of migration has yet to be determined. 
regulation and functions of tissue resident ILC2s in various inflammatory conditions. In contrast, our understanding of what happens to ILC2s after activation and resolution of inflammation is still limited. While the majority of activated ILC2s are expected to die as the ILC2 population contracts after the peak of inflammation, some may become memory-like ILC2s, exhausted ILC2s, ex-ILC2s, or circulatory ILC2s, as summarized in this review. Considering that humans are continuously exposed to extrinsic insults, our ILC2s are presumably activated at some point. Therefore, we will likely benefit from future research on the dynamics of ILC2s after activation in various organs and the functional significance of previously activated ILC2s in inflammation at local and distant sites. It remains to be elucidated how and why activated tissue resident ILC2s take different pathways, namely death, memory, exhaustion, transdifferentiation or migration and whether it is predetermined by neonatal training or decided during activation.

\section{REFERENCES}

1. Vivier E, Artis D, Colonna M, Diefenbach A, Di Santo JP, Eberl G, et al. Innate Lymphoid Cells: 10 Years on. Cell (2018) 174:1054-66. doi: 10.1016/ j.cell.2018.07.017

2. Moro K, Yamada T, Tanabe M, Takeuchi T, Ikawa T, Kawamoto H, et al. Innate Production of $\mathrm{T}(\mathrm{H}) 2$ Cytokines by Adipose Tissue-Associated C-Kit (+)Sca-1(+) Lymphoid Cells. Nature (2010) 463:540-4. doi: 10.1038/ nature 08636

3. Neill DR, Wong SH, Bellosi A, Flynn RJ, Daly M, Langford TKA, et al. Nuocytes Represent a New Innate Effector Leukocyte That Mediates Type-2 Immunity. Nature (2010) 464:1367-70. doi: 10.1038/nature08900

4. Price AE, Liang H-E, Sullivan BM, Reinhardt RL, Eisley CJ, Erle DJ, et al. Systemically Dispersed Innate IL-13-Expressing Cells in Type 2 Immunity. Proc Natl Acad Sci U S A (2010) 107:11489-94. doi: 10.1073/ pnas. 1003988107

5. Spits H, Artis D, Colonna M, Diefenbach A, Di Santo JP, Eberl G, et al. Innate Lymphoid Cells-a Proposal for Uniform Nomenclature. Nat Rev Immunol (2013) 13:145-9. doi: 10.1038/nri3365

6. Monticelli LA, Sonnenberg GF, Abt MC, Alenghat T, Ziegler CGK, Doering TA, et al. Innate Lymphoid Cells Promote Lung-Tissue Homeostasis After Infection With Influenza Virus. Nat Immunol (2011) 12:1045-54. doi: 10.1038/ni.2131

7. Halim TYF, Krauss RH, Sun AC, Takei F. Lung Natural Helper Cells are a Critical Source of Th2 Cell-Type Cytokines in Protease Allergen-Induced Airway Inflammation. Immunity (2012) 36:451-63. doi: 10.1016/ j.immuni.2011.12.020

8. Chang YJ, Kim HY, Albacker LA, Baumgarth N, McKenzie ANJ, Smith DE, et al. Innate Lymphoid Cells Mediate Influenza-Induced Airway HyperReactivity Independently of Adaptive Immunity. Nat Immunol (2011) 12:631-8. doi: 10.1038/ni.2045

9. Kim BS, Siracusa MC, Saenz SA, Noti M, Monticelli LA, Sonnenberg GF, et al. TSLP Elicits IL-33-Independent Innate Lymphoid Cell Responses to Promote Skin Inflammation. Sci Transl Med (2013) 5:170ra16. doi: 10.1126/ scitranslmed.3005374

10. Salimi M, Barlow JL, Saunders SP, Xue L, Gutowska-Owsiak D, Wang X, et al. A Role for IL-25 and IL-33-Driven Type-2 Innate Lymphoid Cells in Atopic Dermatitis. J Exp Med (2013) 210:2939-50. doi: 10.1084/ jem. 20130351

11. Roediger B, Kyle R, Yip KH, Sumaria N, Guy TV, Kim BS, et al. Cutaneous Immunosurveillance and Regulation of Inflammation by Group 2 Innate Lymphoid Cells. Nat Immunol (2013) 14:564-73. doi: 10.1038/ni.2584

12. Molofsky AB, Nussbaum JC, Liang HE, Dyken SJV, Cheng LE, Mohapatra A, et al. Innate Lymphoid Type 2 Cells Sustain Visceral Adipose Tissue
Finding specific markers for individual ILC2 populations will help us understand the processes.

\section{AUTHOR CONTRIBUTIONS}

LM wrote and edited the manuscript and generated the figures and tables. IM-G and CS wrote and edited the manuscript. FT reviewed the drafts, provided critical input and edited the manuscript and figures. All authors contributed to the article and approved the submitted version.

\section{FUNDING}

This work was supported by a grant from the Canadian Institute of Health Research (PJT-153304).
Eosinophils and Alternatively Activated Macrophages. J Exp Med (2013) 210:535-49. doi: 10.1084/jem.20121964

13. Brestoff JR, Kim BS, Saenz SA, Stine RR, Monticelli LA, Sonnenberg GF, et al. Group 2 Innate Lymphoid Cells Promote Beiging of White Adipose Tissue and Limit Obesity. Nature (2015) 519:242-6. doi: 10.1038/ nature 14115

14. Lee MW, Odegaard JI, Mukundan L, Qiu Y, Molofsky AB, Nussbaum JC, et al. Activated Type 2 Innate Lymphoid Cells Regulate Beige Fat Biogenesis. Cell (2015) 160:74-87. doi: 10.1016/j.cell.2014.12.011

15. Mchedlidze T, Waldner M, Zopf S, Walker J, Rankin A, Schuchmann M, et al. Interleukin-33-Dependent Innate Lymphoid Cells Mediate Hepatic Fibrosis. Immunity (2013) 39:357-71. doi: 10.1016/j.immuni.2013.07.018

16. Dalmas E, Lehmann FM, Dror E, Wueest S, Thienel C, Borsigova M, et al. Interleukin-33-Activated Islet-Resident Innate Lymphoid Cells Promote Insulin Secretion Through Myeloid Cell Retinoic Acid Production. Immunity (2017) 47:928-42.e7. doi: 10.1016/j.immuni.2017.10.015

17. Bracamonte-Baran W, Chen G, Hou X, Talor MV, Choi HS, Davogustto G, et al. Non-Cytotoxic Cardiac Innate Lymphoid Cells are a Resident and Quiescent Type 2-Commited Population. Front Immunol (2019) 10:634. doi: 10.3389/fimmu.2019.00634

18. Choi HS, Won T, Hou X, Chen G, Bracamonte-Baran W, Talor MV, et al. Innate Lymphoid Cells Play a Pathogenic Role in Pericarditis. Cell Rep (2020) 30:2989-3003.e6. doi: 10.1016/j.celrep.2020.02.040

19. Mjösberg JM, Trifari S, Crellin NK, Peters CP, van Drunen CM, Piet B, et al. Human IL-25- and IL-33-Responsive Type 2 Innate Lymphoid Cells are Defined by Expression of CRTH2 and CD161. Nat Immunol (2011) 12:1055-62. doi: 10.1038/ni.2104

20. Schneider C, O’Leary CE, von Moltke J, Liang HE, Ang QY, Turnbaugh PJ, et al. A Metabolite-Triggered Tuft Cell-Ilc2 Circuit Drives Small Intestinal Remodeling. Cell (2018) 174:271-84.e14. doi: 10.1016/j.cell.2018.05.014

21. von Moltke J, Ji M, Liang HE, Locksley RM. Tuft-Cell-Derived IL-25 Regulates an Intestinal ILC2-Epithelial Response Circuit. Nature (2016) 529:221-5. doi: 10.1038/nature16161

22. Ricardo-Gonzalez RR, Van Dyken SJ, Schneider C, Lee J, Nussbaum JC, Liang HE, et al. Tissue Signals Imprint ILC2 Identity With Anticipatory Function. Nat Immunol (2018) 19:1093-9. doi: 10.1038/s41590-018-0201-4

23. Schneider C, Lee J, Koga S, Ricardo-Gonzalez RR, Nussbaum JC, Smith LK, et al. Tissue-Resident Group 2 Innate Lymphoid Cells Differentiate by Layered Ontogeny and in Situ Perinatal Priming. Immunity (2019) 50:1425-38.e5. doi: 10.1016/j.immuni.2019.04.019

24. Steer CA, Martinez-Gonzalez I, Ghaedi M, Allinger P, Mathä L, Takei F. Group 2 Innate Lymphoid Cell Activation in the Neonatal Lung Drives Type 2 Immunity and Allergen Sensitization. J Allergy Clin Immunol (2017) 140:593-5.e3. doi: 10.1016/j.jaci.2016.12.984 
25. de Kleer IM, Kool M, de Bruijn MJW, Willart M, van Moorleghem J, Schuijs MJ, et al. Perinatal Activation of the Interleukin-33 Pathway Promotes Type 2 Immunity in the Developing Lung. Immunity (2016) 45:1285-98. doi: 10.1016/j.immuni.2016.10.031

26. Saluzzo S, Gorki AD, Rana BMJ, Martins R, Scanlon S, Starkl P, et al. FirstBreath-Induced Type 2 Pathways Shape the Lung Immune Environment. Cell Rep (2017) 18:1893-905. doi: 10.1016/j.celrep.2017.01.071

27. Steer CA, Mathä L, Shim H, Takei F. Lung Group 2 Innate Lymphoid Cells are Trained by Endogenous IL-33 in the Neonatal Period. JCI Insight (2020) 5:e135961. doi: 10.1172/JCI.INSIGHT.135961

28. Dutton EE, Camelo A, Sleeman M, Herbst R, Carlesso G, Belz GT, et al. Characterisation of Innate Lymphoid Cell Populations At Different Sites in Mice With Defective T Cell Immunity. Wellcome Open Res (2017) 2:117. doi: 10.12688 /wellcomeopenres.13199.3

29. Martinez-Gonzalez I, Mathä L, Steer CA, Ghaedi M, Poon GFT, Takei F. Allergen-Experienced Group 2 Innate Lymphoid Cells Acquire MemoryLike Properties and Enhance Allergic Lung Inflammation. Immunity (2016) 45:198-208. doi: 10.1016/j.immuni.2016.06.017

30. Lim AI, Menegatti S, Bustamante J, Le Bourhis L, Allez M, Rogge L, et al. IL12 Drives Functional Plasticity of Human Group 2 Innate Lymphoid Cells. J Exp Med (2016) 213:569-83. doi: 10.1084/jem.20151750

31. Simoni Y, Fehlings M, Kløverpris HN, McGovern N, Koo SL, Loh CY, et al. Human Innate Lymphoid Cell Subsets Possess Tissue-Type Based Heterogeneity in Phenotype and Frequency. Immunity (2017) 46:148-61. doi: 10.1016/j.immuni.2016.11.005

32. Hoyler T, Klose CSN, Souabni A, Turqueti-Neves A, Pfeifer D, Rawlins EL, et al. The Transcription Factor GATA-3 Controls Cell Fate and Maintenance of Type 2 Innate Lymphoid Cells. Immunity (2012) 37:634-48. doi: 10.1016/ j.immuni.2012.06.020

33. Mjösberg J, Bernink J, Golebski K, Karrich JJ, Peters CP, Blom B, et al. The Transcription Factor GATA3 is Essential for the Function of Human Type 2 Innate Lymphoid Cells. Immunity (2012) 37:649-59. doi: 10.1016/ j.immuni.2012.08.015

34. Kabata H, Moro K, Koyasu S. The Group 2 Innate Lymphoid Cell (ILC2) Regulatory Network and Its Underlying Mechanisms. Immunol Rev (2018) 286:37-52. doi: 10.1111/imr.12706

35. Hurrell BP, Jahani PS, Akbari O. Social Networking of Group Two Innate Lymphoid Cells in Allergy and Asthma. Front Immunol (2018) 9:2694. doi: 10.3389/fimmu.2018.02694

36. Rider P, Voronov E, Dinarello CA, Apte RN, Cohen I. Alarmins: Feel the Stress. J Immunol (2017) 198:1395-402. doi: 10.4049/jimmunol.1601342

37. Carriere V, Roussel L, Ortega N, Lacorre DA, Americh L, Aguilar L, et al. IL33, the IL-1-Like Cytokine Ligand for ST2 Receptor, is a ChromatinAssociated Nuclear Factor in Vivo. Proc Natl Acad Sci U S A (2007) 104:282-7. doi: 10.1073/pnas.0606854104

38. Moussion C, Ortega N, Girard JP. The IL-1-Like Cytokine IL-33 is Constitutively Expressed in the Nucleus of Endothelial Cells and Epithelial Cells in Vivo: A Novel "Alarmin"? PloS One (2008) 3:e3331. doi: 10.1371/ journal.pone.0003331

39. Küchler AM, Pollheimer J, Balogh J, Sponheim J, Manley L, Sorensen DR, et al. Nuclear Interleukin-33 is Generally Expressed in Resting Endothelium But Rapidly Lost Upon Angiogenic or Proinflammatory Activation. Am J Pathol (2008) 173:1229-42. doi: 10.2353/ajpath.2008.080014

40. Pichery M, Mirey E, Mercier P, Lefrancais E, Dujardin A, Ortega N, et al. Endogenous IL-33 is Highly Expressed in Mouse Epithelial Barrier Tissues, Lymphoid Organs, Brain, Embryos, and Inflamed Tissues: in Situ Analysis Using a Novel Il-33-Lacz Gene Trap Reporter Strain. J Immunol (2012) 188:3488-95. doi: 10.4049/jimmunol.1101977

41. Dahlgren MW, Jones SW, Cautivo KM, Dubinin A, Ortiz-Carpena JF, Farhat S, et al. Adventitial Stromal Cells Define Group 2 Innate Lymphoid Cell Tissue Niches. Immunity (2019) 50:707-22.e6. doi: 10.1016/ j.immuni.2019.02.002

42. Mohapatra A, Van Dyken SJ, Schneider C, Nussbaum JC, Liang HE, Locksley RM. Group 2 Innate Lymphoid Cells Utilize the IRF4-IL-9 Module to Coordinate Epithelial Cell Maintenance of Lung Homeostasis. Mucosal Immunol (2016) 9:275-86. doi: 10.1038/mi.2015.59

43. Kang CM, Jang AS, Ahn MH, Shin JA, Kim JH, Choi YS, et al. Interleukin-25 and Interleukin-13 Production by Alveolar Macrophages in Response to
Particles. Am J Respir Cell Mol Biol (2005) 33:290-6. doi: 10.1165/ rcmb.2005-0003OC

44. Ikeda K, Nakajima H, Suzuki K, Kagami SI, Hirose K, Suto A, et al. Mast Cells Produce Interleukin-25 Upon Fceri-Mediated Activation. Blood (2003) 101:3594-6. doi: 10.1182/blood-2002-09-2817

45. Wang YH, Angkasekwinai P, Lu N, Voo KS, Arima K, Hanabuchi S, et al. IL25 Augments Type 2 Immune Responses by Enhancing the Expansion and Functions of TSLP-DC-Activated Th2 Memory Cells. J Exp Med (2007) 204:1837-47. doi: 10.1084/jem.20070406

46. Fort MM, Cheung J, Yen D, Li J, Zurawski SM, Lo S, et al. IL-25 Induces IL4, IL-5, and IL-13 and Th2-Associated Pathologies in Vivo. Immunity (2001) 15:985-95. doi: 10.1016/s1074-7613(01)00243-6

47. Taylor BC, Zaph C, Troy AE, Du Y, Guild KJ, Comeau MR, et al. TSLP Regulates Intestinal Immunity and Inflammation in Mouse Models of Helminth Infection and Colitis. J Exp Med (2009) 206:655-67. doi: $10.1084 /$ jem.20081499

48. Rimoldi M, Chieppa M, Salucci V, Avogadri F, Sonzogni A, Sampietro GM, et al. Intestinal Immune Homeostasis is Regulated by the Crosstalk Between Epithelial Cells and Dendritic Cells. Nat Immunol (2005) 6:507-14. doi: $10.1038 /$ ni1 192

49. Palmer G, Lipsky BP, Smithgall MD, Meininger D, Siu S, Talabot-Ayer D, et al. The IL-1 Receptor Accessory Protein (Acp) is Required for IL-33 Signaling and Soluble Acp Enhances the Ability of Soluble ST2 to Inhibit IL33. Cytokine (2008) 42:358-64. doi: 10.1016/j.cyto.2008.03.008

50. Monin L, Gaffen SL. Interleukin 17 Family Cytokines: Signaling Mechanisms, Biological Activities, and Therapeutic Implications. Cold Spring Harb Perspect Biol (2018) 10:a028522. doi: 10.1101/ cshperspect.a028522

51. Schmitz J, Owyang A, Oldham E, Song Y, Murphy E, McClanahan TK, et al. IL-33, an Interleukin-1-Like Cytokine That Signals Via the IL-1 ReceptorRelated Protein ST2 and Induces T Helper Type 2-Associated Cytokines. Immunity (2005) 23:479-90. doi: 10.1016/j.immuni.2005.09.015

52. Furusawa J, Moro K, Motomura Y, Okamoto K, Zhu J, Takayanagi H, et al Critical Role of P38 and GATA3 in Natural Helper Cell Function. J Immunol (2013) 191:1818-26. doi: 10.4049/jimmunol.1300379

53. Roan F, Obata-Ninomiya K, Ziegler SF. Epithelial Cell-Derived Cytokines: More Than Just Signaling the Alarm. J Clin Invest (2019) 129:1441-51. doi: 10.1172/JCI124606

54. Rochman Y, Kashyap M, Robinson GW, Sakamoto K, Gomez-Rodriguez J, Wagner KU, et al. Thymic Stromal Lymphopoietin-Mediated STAT5 Phosphorylation Via Kinases JAK1 and JAK2 Reveals a Key Difference From IL-7-Induced Signaling. Proc Natl Acad Sci U S A (2010) 107:1945560. doi: $10.1073 /$ pnas.1008271107

55. Guo L, Wei G, Zhu J, Liao W, Leonard WJ, Zhao K, et al. IL-1 Family Members and STAT Activators Induce Cytokine Production by Th2, Th17, and Th1 Cells. Proc Natl Acad Sci U S A (2009) 106:13463-8. doi: 10.1073/ pnas.0906988106

56. Klein Wolterink RGJ, Kleinjan A, van Nimwegen M, Bergen I, de Bruijn M, Levani Y, et al. Pulmonary Innate Lymphoid Cells are Major Producers of IL-5 and IL-13 in Murine Models of Allergic Asthma. Eur J Immunol (2012) 42:1106-16. doi: 10.1002/eji.201142018

57. Li Y, Chen S, Chi Y, Yang Y, Chen X, Wang H, et al. Kinetics of the Accumulation of Group 2 Innate Lymphoid Cells in IL-33-Induced and IL25-Induced Murine Models of Asthma: A Potential Role for the Chemokine CXCL16. Cell Mol Immunol (2019) 16:75-86. doi: 10.1038/s41423-018$0182-0$

58. Barlow JL, Bellosi A, Hardman CS, Drynan LF, Wong SH, Cruickshank JP, et al. Innate IL-13-Producing Nuocytes Arise During Allergic Lung Inflammation and Contribute to Airways Hyperreactivity. J Allergy Clin Immunol (2012) 129:191-8.e1-4. doi: 10.1016/j.jaci.2011.09.041

59. Barlow JL, Peel S, Fox J, Panova V, Hardman CS, Camelo A, et al. IL-33 is More Potent Than IL-25 in Provoking IL-13-Producing Nuocytes (Type 2 Innate Lymphoid Cells) and Airway Contraction. J Allergy Clin Immunol (2013) 132:933-41. doi: 10.1016/j.jaci.2013.05.012

60. Li BWS, Stadhouders R, de Bruijn MJW, Lukkes M, Beerens DMJM, Brem MD, et al. Group 2 Innate Lymphoid Cells Exhibit a Dynamic Phenotype in Allergic Airway Inflammation. Front Immunol (2017) 8:1684. doi: 10.3389/ fimmu.2017.01684 
61. Gold MJ, Antignano F, Halim TYF, Hirota JA, Blanchet MR, Zaph C, et al. Group 2 Innate Lymphoid Cells Facilitate Sensitization to Local, But Not Systemic, TH2-Inducing Allergen Exposures. J Allergy Clin Immunol (2014) 133:1142-8. doi: 10.1016/j.jaci.2014.02.033

62. Van Dyken SJ, Mohapatra A, Nussbaum JC, Molofsky AB, Thornton EE, Ziegler SF, et al. Chitin Activates Parallel Immune Modules That Direct Distinct Inflammatory Responses Via Innate Lymphoid Type 2 and $\Gamma \delta \mathrm{T}$ Cells. Immunity (2014) 40:414-24. doi: 10.1016/j.immuni.2014.02.003

63. Halim TYF, Steer CA, Mathä L, Gold MJ, Martinez-Gonzalez I, McNagny $\mathrm{KM}$, et al. Group 2 Innate Lymphoid Cells are Critical for the Initiation of Adaptive T Helper 2 Cell-Mediated Allergic Lung Inflammation. Immunity (2014) 40:425-35. doi: 10.1016/j.immuni.2014.01.011

64. Bartemes KR, Iijima K, Kobayashi T, Kephart GM, McKenzie AN, Kita H. IL-33-Responsive Lineage- CD25+ CD44(Hi) Lymphoid Cells Mediate Innate Type 2 Immunity and Allergic Inflammation in the Lungs. J Immunol (2012) 188:1503-13. doi: 10.4049/jimmunol.1102832

65. Zhou W, Toki S, Zhang J, Goleniewksa K, Newcomb DC, Cephus JY, et al. Prostaglandin I2 Signaling and Inhibition of Group 2 Innate Lymphoid Cell Responses. Am J Respir Crit Care Med (2016) 193:31-42. doi: 10.1164/ rccm.201410-1793OC

66. Doherty TA, Khorram N, Chang JE, Kim HK, Rosenthal P, Croft M, et al. STAT6 Regulates Natural Helper Cell Proliferation During Lung Inflammation Initiated by Alternaria. Am J Physiol Lung Cell Mol Physiol (2012) 303:L577-88. doi: 10.1152/ajplung.00174.2012

67. Hammad H, Chieppa M, Perros F, Willart MA, Germain RN, Lambrecht BN. House Dust Mite Allergen Induces Asthma Via Toll-Like Receptor 4 Triggering of Airway Structural Cells. Nat Med (2009) 15:410-6. doi: $10.1038 / \mathrm{nm} .1946$

68. Post S, Nawijn MC, Hackett TL, Baranowska M, Gras R, Van Oosterhout AJM, et al. The Composition of House Dust Mite is Critical for Mucosal Barrier Dysfunction and Allergic Sensitisation. Thorax (2012) 67:488-95. doi: 10.1136/thoraxjnl-2011-200606

69. Moro K, Kabata H, Tanabe M, Koga S, Takeno N, Mochizuki M, et al. Interferon and IL-27 Antagonize the Function of Group 2 Innate Lymphoid Cells and Type 2 Innate Immune Responses. Nat Immunol (2016) 17:76-86. doi: 10.1038/ni.3309

70. Li BWS, de Bruijn MJW, Tindemans I, Lukkes M, KleinJan A, Hoogsteden HC, et al. T Cells are Necessary for ILC2 Activation in House Dust MiteInduced Allergic Airway Inflammation in Mice. Eur J Immunol (2016) 46:1392-403. doi: 10.1002/eji.201546119

71. Wilhelm C, Hirota K, Stieglitz B, Van Snick J, Tolaini M, Lahl K, et al. An IL9 Fate Reporter Demonstrates the Induction of an Innate IL-9 Response in Lung Inflammation. Nat Immunol (2011) 12:1071-7. doi: 10.1038/ni.2133

72. Turner JE, Morrison PJ, Wilhelm C, Wilson M, Ahlfors H, Renauld JC, et al. IL-9-Mediated Survival of Type 2 Innate Lymphoid Cells Promotes Damage Control in Helminth-Induced Lung Inflammation. J Exp Med (2013) 210:2951-65. doi: 10.1084/jem.20130071

73. Kouro T, Takatsu K. IL-5- and Eosinophil-Mediated Inflammation: From Discovery to Therapy. Int Immunol (2009) 21:1303-9. doi: 10.1093/intimm/ dxp 102

74. Gour N, Wills-Karp M. IL-4 and IL-13 Signaling in Allergic Airway Disease. Cytokine (2015) 75:68-78. doi: 10.1016/j.cyto.2015.05.014

75. Sugita K, Steer CA, Martinez-Gonzalez I, Altunbulakli C, Morita H, CastroGiner F, et al. Type 2 Innate Lymphoid Cells Disrupt Bronchial Epithelial Barrier Integrity by Targeting Tight Junctions Through IL-13 in Asthmatic Patients. J Allergy Clin Immunol (2018) 141:300-10.e11. doi: 10.1016/ j.jaci.2017.02.038

76. Townsend MJ, Fallon PG, Matthews DJ, Smith P, Jolin HE, McKenzie ANJ. IL-9-Deficient Mice Establish Fundamental Roles for IL-9 in Pulmonary Mastocytosis and Goblet Cell Hyperplasia But Not T Cell Development. Immunity (2000) 13:573-83. doi: 10.1016/S1074-7613(00)00056-X

77. Kearley J, Erjefalt JS, Andersson C, Benjamin E, Jones CP, Robichaud A, et al. IL-9 Governs Allergen-Induced Mast Cell Numbers in the Lung and Chronic Remodeling of the Airways. Am J Respir Crit Care Med (2011) 183:865-75. doi: 10.1164/rccm.200909-1462OC

78. Seehus CR, Kadavallore A, Torre BD La, Yeckes AR, Wang Y, Tang J, et al. Alternative Activation Generates IL-10 Producing Type 2 Innate Lymphoid Cells. Nat Commun (2017) 8:1900. doi: 10.1038/s41467-017-02023-Z
79. Miyamoto C, Kojo S, Yamashita M, Moro K, Lacaud G, Shiroguchi K, et al. Runx/Cbf $\beta$ Complexes Protect Group 2 Innate Lymphoid Cells From Exhausted-Like Hyporesponsiveness During Allergic Airway Inflammation. Nat Commun (2019) 10:447. doi: 10.1038/s41467-01908365-0

80. Bando JK, Gilfillan S, Di Luccia B, Fachi JL, Sécca C, Cella M, et al. ILC2s are the Predominant Source of Intestinal ILC-Derived IL-10. J Exp Med (2020) 217:e20191520. doi: 10.1084/jem.20191520

81. Golebski K, Layhadi JA, Sahiner U, Steveling-Klein EH, Lenormand MM, Li RCY, et al. Induction of IL-10-Producing Type 2 Innate Lymphoid Cells by Allergen Immunotherapy is Associated With Clinical Response. Immunity (2021) 54:291-307.e7. doi: 10.1016/j.immuni.2020.12.013

82. Morita H, Kubo T, Rückert B, Ravindran A, Soyka MB, Rinaldi AO, et al. Induction of Human Regulatory Innate Lymphoid Cells From Group 2 Innate Lymphoid Cells by Retinoic Acid. J Allergy Clin Immunol (2019) 143:2190-201.e9. doi: 10.1016/j.jaci.2018.12.1018

83. Schwartz C, Khan AR, Floudas A, Saunders SP, Hams E, Rodewald HR, et al ILC2s Regulate Adaptive Th2 Cell Functions Via PD-L1 Checkpoint Control. J Exp Med (2017) 214:2507-21. doi: 10.1084/jem.20170051

84. Halim TYF, Rana BMJ, Walker JA, Kerscher B, Knolle MD, Jolin HE, et al. Tissue-Restricted Adaptive Type 2 Immunity is Orchestrated by Expression of the Costimulatory Molecule OX40L on Group 2 Innate Lymphoid Cells. Immunity (2018) 48:1195-207.e6. doi: 10.1016/j.immuni.2018.05.003

85. Molofsky AB, Van Gool F, Liang H-E, Van Dyken SJ, Nussbaum JC, Lee J et al. Interleukin-33 and Interferon- $\Gamma$ Counter-Regulate Group 2 Innate Lymphoid Cell Activation During Immune Perturbation. Immunity (2015) 43:161-74. doi: 10.1016/j.immuni.2015.05.019

86. Maazi H, Patel N, Sankaranarayanan I, Suzuki Y, Rigas D, Soroosh P, et al. ICOS:ICOS-Ligand Interaction is Required for Type 2 Innate Lymphoid Cell Function, Homeostasis, and Induction of Airway Hyperreactivity. Immunity (2015) 42:538-51. doi: 10.1016/j.immuni.2015.02.007

87. Christianson CA, Goplen NP, Zafar I, Irvin C, Good JT, Rollins DR, et al Persistence of Asthma Requires Multiple Feedback Circuits Involving Type 2 Innate Lymphoid Cells and IL-33. J Allergy Clin Immunol (2015) 136:5968.e14. doi: 10.1016/j.jaci.2014.11.037

88. Bartemes KR, Kephart GM, Fox SJ, Kita H. Enhanced Innate Type 2 Immune Response in Peripheral Blood From Patients With Asthma. J Allergy Clin Immunol (2014) 134:671-8.e4. doi: 10.1016/j.jaci.2014.06.024

89. Poposki JA, Klingler AI, Tan BK, Soroosh P, Banie H, Lewis G, et al. Group 2 Innate Lymphoid Cells are Elevated and Activated in Chronic Rhinosinusitis With Nasal Polyps. Immun Inflammation Dis (2017) 5:233-43. doi: 10.1002/ iid3.161

90. Shaw JL, Fakhri S, Citardi MJ, Porter PC, Corry DB, Kheradmand F, et al. IL33-Responsive Innate Lymphoid Cells are an Important Source of IL-13 in Chronic Rhinosinusitis With Nasal Polyps. Am J Respir Crit Care Med (2013) 188:432-9. doi: 10.1164/rccm.201212-2227OC

91. Walford HH, Lund SJ, Baum RE, White AA, Bergeron CM, Husseman J, et al. Increased ILC2s in the Eosinophilic Nasal Polyp Endotype are Associated With Corticosteroid Responsiveness. Clin Immunol (2014) 155:126-35. doi: 10.1016/j.clim.2014.09.007

92. Ho J, Bailey M, Zaunders J, Mrad N, Sacks R, Sewell W, et al. Group 2 Innate Lymphoid Cells (ILC2s) are Increased in Chronic Rhinosinusitis With Nasal Polyps or Eosinophilia. Clin Exp Allergy (2015) 45:394-403. doi: 10.1111/ cea.12462

93. Tojima I, Kouzaki H, Shimizu S, Ogawa T, Arikata M, Kita H, et al. Group 2 Innate Lymphoid Cells are Increased in Nasal Polyps in Patients With Eosinophilic Chronic Rhinosinusitis. Clin Immunol (2016) 170:1-8 doi: 10.1016/j.clim.2016.07.010

94. Dhariwal J, Cameron A, Trujillo-Torralbo MB, Del Rosario A, Bakhsoliani E, Paulsen M, et al. Mucosal Type 2 Innate Lymphoid Cells are a Key Component of the Allergic Response to Aeroallergens. Am J Respir Crit Care Med (2017) 195:1586-96. doi: 10.1164/rccm.201609-1846OC

95. Hams E, Armstrong ME, Barlow JL, Saunders SP, Schwartz C, Cooke G, et al. IL-25 and Type 2 Innate Lymphoid Cells Induce Pulmonary Fibrosis. Proc Natl Acad Sci U S A (2014) 111:367-72. doi: 10.1073/pnas.1315854111

96. Zhao Y, De Los Santos FG, Wu Z, Liu T, Phan SH. An ST2-Dependent Role of Bone Marrow-Derived Group 2 Innate Lymphoid Cells in Pulmonary Fibrosis. J Pathol (2018) 245:399-409. doi: 10.1002/path.5092 
97. Li D, Guabiraba R, Besnard AG, Komai-Koma M, Jabir MS, Zhang L, et al. IL-33 Promotes ST2-Dependent Lung Fibrosis by the Induction of Alternatively Activated Macrophages and Innate Lymphoid Cells in Mice. J Allergy Clin Immunol (2014) 134:1422-32.e11. doi: 10.1016/ j.jaci.2014.05.011

98. Stier MT, Bloodworth MH, Toki S, Newcomb DC, Goleniewska K, Boyd KL, et al. Respiratory Syncytial Virus Infection Activates IL-13-Producing Group 2 Innate Lymphoid Cells Through Thymic Stromal Lymphopoietin. J Allergy Clin Immunol (2016) 138:814-24.e11. doi: 10.1016/j.jaci.2016.01.050

99. Vu LD, Siefker D, Jones TL, You D, Taylor R, DeVincenzo J, et al. Elevated Levels of Type 2 Respiratory Innate Lymphoid Cells in Human Infants With Severe Respiratory Syncytial Virus Bronchiolitis. Am J Respir Crit Care Med (2019) 200:1414-23. doi: 10.1164/rccm.201812-2366OC

100. Gasteiger G, Fan X, Dikiy S, Lee SY, Rudensky AY. Tissue Residency of Innate Lymphoid Cells in Lymphoid and Nonlymphoid Organs. Science (2015) 350:981-5. doi: 10.1126/science.aac9593

101. Ricardo-Gonzalez RR, Schneider C, Liao C, Lee J, Liang H-E, Locksley RM. Tissue-Specific Pathways Extrude Activated ILC2s to Disseminate Type 2 Immunity. J Exp Med (2020) 217:e20191172. doi: 10.1084/jem.20191172

102. Bal SM, Bernink JH, Nagasawa M, Groot J, Shikhagaie MM, Golebski K, et al. IL-1 $\beta$, IL-4 and IL-12 Control the Fate of Group 2 Innate Lymphoid Cells in Human Airway Inflammation in the Lungs. Nat Immunol (2016) 17:636-45. doi: $10.1038 /$ ni.3444

103. Silver JS, Kearley J, Copenhaver AM, Sanden C, Mori M, Yu L, et al. Inflammatory Triggers Associated With Exacerbations of COPD Orchestrate Plasticity of Group 2 Innate Lymphoid Cells in the Lungs. Nat Immunol (2016) 17:626-35. doi: 10.1038/ni.3443

104. Ohne Y, Silver JS, Thompson-Snipes LA, Collet MA, Blanck JP, Cantarel BL, et al. IL-1 is a Critical Regulator of Group 2 Innate Lymphoid Cell Function and Plasticity. Nat Immunol (2016) 17:646-55. doi: 10.1038/ni.3447

105. Bernink JH, Ohne Y, Teunissen MBM, Wang J, Wu J, Krabbendam L, et al. C-Kit-Positive ILC2s Exhibit an ILC3-Like Signature That May Contribute to IL-17-Mediated Pathologies. Nat Immunol (2019) 20:992-1003. doi: 10.1038/s41590-019-0423-0

106. Golebski K, Ros XR, Nagasawa M, van Tol S, Heesters BA, Aglmous H, et al. IL-1 $\beta$, IL-23, and TGF-B Drive Plasticity of Human ILC2s Towards IL-17Producing Ilcs in Nasal Inflammation. Nat Commun (2019) 10:2162. doi: 10.1038/s41467-019-09883-7

107. Huang Y, Mao K, Chen X, Sun MA, Kawabe T, Li W, et al. S1P-Dependent Interorgan Trafficking of Group 2 Innate Lymphoid Cells Supports Host Defense. Science (2018) 359:114-9. doi: 10.1126/science.aam5809

108. Yasuda K, Adachi T, Koida A, Nakanishi K. Nematode-Infected Mice Acquire Resistance to Subsequent Infection With Unrelated Nematode by Inducing Highly Responsive Group 2 Innate Lymphoid Cells in the Lung. Front Immunol (2018) 9:2132. doi: 10.3389/fimmu.2018.02132

109. Huang Y, Guo L, Qiu J, Chen X, Hu-Li J, Siebenlist U, et al. IL-25Responsive, Lineage-Negative KLRG1 Hi Cells are Multipotential "Inflammatory" Type 2 Innate Lymphoid Cells. Nat Immunol (2015) 16:161-9. doi: 10.1038/ni.3078

110. O'Leary JG, Goodarzi M, Drayton DL, von Andrian UH. T Cell- and B CellIndependent Adaptive Immunity Mediated by Natural Killer Cells. Nat Immunol (2006) 7:507-16. doi: 10.1038/ni1332
111. Paust S, Gill HS, Wang BZ, Flynn MP, Moseman EA, Senman B, et al. Critical Role for the Chemokine Receptor CXCR6 in NK Cell-Mediated Antigen-Specific Memory of Haptens and Viruses. Nat Immunol (2010) 11:1127-35. doi: 10.1038/ni.1953

112. Sun JC, Beilke JN, Lanier LL. Adaptive Immune Features of Natural Killer Cells. Nature (2009) 457:557-61. doi: 10.1038/nature07833

113. Cooper MA, Elliott JM, Keyel PA, Yang L, Carrero JA, Yokoyama WM. Cytokine-Induced Memory-Like Natural Killer Cells. Proc Natl Acad Sci U S A (2009) 106:1915-9. doi: 10.1073/pnas.0813192106

114. Martinez-Gonzalez I, Mathä L, Steer CA, Takei F. Immunological Memory of Group 2 Innate Lymphoid Cells. Trends Immunol (2017) 38:423-31. doi: 10.1016/j.it.2017.03.005

115. Martinez-Gonzalez I, Ghaedi M, Steer CA, Mathä L, Vivier E, Takei F. ILC2 Memory: Recollection of Previous Activation. Immunol Rev (2018) 283:4153. doi: 10.1111/imr.12643

116. Guo L, Huang Y, Chen X, Hu-Li J, Urban JF, Paul WE. Innate Immunological Function of T H2 Cells in Vivo. Nat Immunol (2015) 16:1051-9. doi: 10.1038/ni.3244

117. Romee R, Schneider SE, Leong JW, Chase JM, Keppel CR, Sullivan RP, et al. Cytokine Activation Induces Human Memory-Like NK Cells. Blood (2012) 120:4751-60. doi: 10.1182/blood-2012-04-419283

118. Foley B, Cooley S, Verneris MR, Curtsinger J, Luo X, Waller EK, et al. Human Cytomegalovirus (CMV)-Induced Memory-Like NKG2C + NK Cells are Transplantable and Expand in Vivo in Response to Recipient CMV Antigen. J Immunol (2012) 189:5082-8. doi: 10.4049/ jimmunol.1201964

119. van der Ploeg EK, Golebski K, van Nimwegen M, Fergusson JR, Heesters BA, Martinez-Gonzalez I, et al. Steroid-Resistant Human Inflammatory ILC2s are Marked by CD45RO and Elevated in Type 2 Respiratory Diseases. Sci Immunol (2021) 6:eabd3489. doi: 10.1126/sciimmunol.abd3489

120. Gray D. Immunological Memory. Annu Rev Immunol (1993) 11:49-77. doi: 10.1146/annurev.iy.11.040193.000405

121. Cheon IS, Son YM, Jiang L, Goplen NP, Kaplan MH, Limper AH, et al. Neonatal Hyperoxia Promotes Asthma-Like Features Through IL-33Dependent ILC2 Responses. J Allergy Clin Immunol (2018) 142:1100-12. doi: 10.1016/j.jaci.2017.11.025

122. McLane LM, Abdel-Hakeem MS, Wherry EJ. CD8 T Cell Exhaustion During Chronic Viral Infection and Cancer. Annu Rev Immunol (2019) 37:457-95. doi: 10.1146/annurev-immunol-041015-055318

123. Urban JF, Madden KB, Svetić A, Cheever A, Trotta PP, Gause WC, et al. The Importance of Th2 Cytokines in Protective Immunity to Nematodes. Immunol Rev (1992) 127:205-20. doi: 10.1111/j.1600-065X.1992.tb01415.x

Conflict of Interest: The authors declare that the research was conducted in the absence of any commercial or financial relationships that could be construed as a potential conflict of interest.

Copyright (c) 2021 Mathä, Martinez-Gonzalez, Steer and Takei. This is an open-access article distributed under the terms of the Creative Commons Attribution License (CC BY). The use, distribution or reproduction in other forums is permitted, provided the original author(s) and the copyright owner(s) are credited and that the original publication in this journal is cited, in accordance with accepted academic practice. No use, distribution or reproduction is permitted which does not comply with these terms. 